\title{
Infiltration of liposome bupivacaine into the transversus abdominis plane for postsurgical analgesia in robotic laparoscopic prostatectomy: a pilot study
}

\author{
This article was published in the following Dove Press journal: \\ Local and Regional Anesthesia \\ 12 December 2014 \\ Number of times this article has been viewed
}

\author{
Andrew Sternlicht' \\ Max Shapiro' \\ Gary Robelen' \\ Usha Vellayappan' \\ Ingolf A Tuerk ${ }^{2}$
}

'Department of Anesthesiology and Pain Medicine, ${ }^{2}$ Department of Urology, Steward St Elizabeth's Medical Center, Tufts University School of Medicine, Boston, MA, USA
Correspondence: Andrew Sternlicht CAP Anesthesia PC, St Elizabeth's Medical Center, 736 Cambridge St, Department of Anesthesiology and Pain Medicine, Brighton, MA 02135, USA

Tel +l 6177892782

Fax +l 6172546384

Email andrew.sternlicht@steward.org
Background: Transversus abdominis plane (TAP) infiltration has been increasingly used for postsurgical analgesia in abdominal/pelvic procedures; however, duration/extent of analgesia with standard local anesthetics is limited. This pilot study assessed the preliminary efficacy and safety of two volumes of liposome bupivacaine administered via TAP infiltration in patients undergoing robotic laparoscopic prostatectomy.

Methods: In this single-center, open-label, prospective study, patients older than 18 years received TAP infiltration with liposome bupivacaine immediately after surgery. The first 12 patients received a total volume of $20 \mathrm{~mL}$ liposome bupivacaine $(266 \mathrm{mg})$; the next 12 received $40 \mathrm{~mL}$ liposome bupivacaine ( $266 \mathrm{mg}$ ). The liposome bupivacaine was diluted with $0.9 \%$ normal saline. The primary efficacy measure was duration of analgesia, measured by time to first opioid administration. Secondary outcome measures included patient-assessed pain scores, opioid use, and opioid-related adverse events (AEs).

Results: Twenty-four patients received liposome bupivacaine $(20 \mathrm{~mL}, \mathrm{n}=12 ; 40 \mathrm{~mL}, \mathrm{n}=12)$ and were included in the primary analysis. Three refused participation in a 10-day follow-up visit and did not complete the study. Median time to first opioid administration after surgery was 23 and 26 minutes for the 20 and $40 \mathrm{~mL}$ groups, respectively. Mean total amount of postsurgical opioids ranged from 25.4 to $27.3 \mathrm{mg}$; after hospital discharge to day 10, both groups required a mean of 0.7 oxycodone/acetaminophen tablets/day. Mean pain scores of 4.4 and 5.3 were reported at 1 hour and 3.1 and 3.9 at 2 hours postsurgery, with 20 and $40 \mathrm{~mL}$ doses, respectively. Neither group had mean scores higher than 3.0 at any further assessments. No opioid-related or treatment-related serious AEs were reported.

Conclusion: Median time to first opioid administration did not differ between the two groups. No differences in secondary outcomes were observed on the basis of volume administered. These initial findings suggest further study of liposome bupivacaine administered via TAP infiltration as part of a multimodal analgesic regimen in laparoscopic robotic prostatectomy may be warranted.

Keywords: transversus abdominis plane infiltration, laparoscopic prostatectomy, postsurgical analgesia, liposome bupivacaine

\section{Introduction}

Appropriate management of postsurgical pain is a key factor in timely patient recovery after surgery. ${ }^{1}$ Opioids are currently a mainstay of therapy for pain management in the postoperative abdominal/pelvic surgery patient ${ }^{2}$ and are associated with many potential adverse effects such as sedation, constipation, nausea and vomiting, and 
respiratory depression. ${ }^{3}$ Multimodal analgesia strategies have been recognized as a potential method to improve postsurgical pain management while minimizing opioidrelated adverse effects. ${ }^{1}$ Regional anesthetic infiltration into the transversus abdominis plane (TAP) has gained enormous popularity in the past several years to provide postoperative analgesia after abdominal/pelvic surgical procedures such as hysterectomy, ileostomy reversals, cesarian delivery, and radical prostatectomy. In these settings, TAP infiltration has demonstrated reductions in postoperative opioid requirements, improvements in pain scores, reduced opioid-related adverse effects, faster return of gastrointestinal function, and earlier hospital discharge compared with traditional parenterally administered analgesic techniques..$^{4-6}$

The duration of postoperative analgesia with TAP infiltration has been reported to vary from 12 to 48 hours with the use of various doses and adjuncts to local anesthetics. ${ }^{7-9}$ In a previous study of TAP infiltration conducted by our group in patients undergoing robotic prostatectomy using large-volume $(79 \mathrm{~mL})$ dilute $0.125 \%$ bupivacaine $\mathrm{HCl}$ with and without the addition of low-dose dexamethasone, ${ }^{10}$ the average duration of efficacy was approximately 12 hours without and 16 hours with the addition of dexamethasone. However, patients often experience pain beyond the duration of TAP block after abdominal/pelvic surgery, and once the block wears off, patients are typically treated with opioids to manage their pain. ${ }^{2}$ Techniques to prolong TAP infiltration efficacy include the addition of adjunctive agents such as dexamethasone, increasing the dose of local anesthetics, and placing catheters in the TAP and continuously infusing dilute local anesthetic into the plane, but this option is associated with the possibility of infection and catheter dislodgement, as well as limitations on patient mobility postoperatively. ${ }^{2}$

Liposome bupivacaine (EXPAREL, bupivacaine liposome injectable suspension; Pacira Pharmaceuticals, Inc., Parsippany, NJ, USA) is a novel multivesicular formulation of bupivacaine shown to provide postsurgical analgesia and reduce opioid use for up to 72 hours in a soft tissue surgical model (hemorrhoidectomy) after a single intraoperative administration via local infiltration into the surgical site. ${ }^{11}$ The objectives of this pilot study were to assess the preliminary efficacy and safety of liposome bupivacaine in TAP infiltration in patients undergoing robotic laparoscopic prostatectomy and to assess whether gross changes in the volume of liposome bupivacaine infiltrated, while delivering the identical dose, influenced the magnitude and duration of resultant analgesia.

\section{Materials and methods}

This single-center, prospective, open-label, nonrandomized study evaluated the preliminary efficacy and safety of two different volume levels of liposome bupivacaine via TAP infiltration in the setting of robotic laparoscopic prostatectomy. The study was conducted at Steward St. Elizabeth's Medical Center (Brighton, MA, USA) from March 2012 to May 2012. TAP infiltrations were performed by three attending anesthesiologists; all surgeries were performed by a single surgeon. The protocol was approved by the Steward St Elizabeth's institutional review board, and the study was conducted in accordance with the International Conference on Harmonisation Good Clinical Practice guidelines. ${ }^{12}$ All patients provided written informed consent before any study procedures were conducted. The study has been registered at http://www.clinicaltrials.gov under Clinical Trials Identifier NCT01582477.

\section{Patients}

Male patients between 18 and 75 years of age with an American Society of Anesthesiologists Physical Status classification of 1, 2, or 3 undergoing robotic laparoscopic prostatectomy were eligible for inclusion in the study.

Patients were excluded from participation in the study if they demonstrated hypersensitivity or idiosyncratic reactions to amide-type local anesthetics; were unable to tolerate oxycodone with acetaminophen; had anatomy or required a surgical procedure that, in the opinion of the investigator, would preclude the successful performance of TAP infiltration; had received any investigational drug within 30 days before study drug administration; or had planned administration of another investigational product or procedure during participation in this study.

\section{Study procedures}

Bilateral TAP infiltrations were performed in the operating room immediately after robotic prostatectomy while the patient was still anesthetized. All patients were to receive a total of $266 \mathrm{mg}$ liposome bupivacaine (133 mg liposome bupivacaine per side) to establish bilateral TAP infiltration. The first twelve patients received this dose in a total volume of $20 \mathrm{~mL}$ ( $10 \mathrm{~mL}$ per side). The next twelve patients received this same dose in a total volume of $40 \mathrm{~mL}$ (20 mL per side); liposome bupivacaine was diluted with preservative-free $0.9 \%$ normal saline. Ultrasound guidance was required, and every effort was to be made to ensure that all anesthesiologists participating in this study followed a standardized technique for TAP infiltration, including using the same syringe size, needle gauge, needle placement, and rate of injection in all patients. 
Using an in-plane technique, the ultrasound probe was placed on the caudad (infraumbilical) anterolateral abdominal wall between the iliac crest and the subcostal margin to view the three abdominal muscle layers. The needle was inserted through the muscle layers until the tip entered the layer between the internal oblique muscle and transversus muscle, at which point the liposome bupivacaine was injected.

Only short-acting opioids (fentanyl) were permitted intraoperatively; longer-acting opioids, such as morphine or hydromorphone, acetaminophen, nonsteroidal anti-inflammatory drugs, and other analgesics, were not permitted unless used to treat adverse events (AEs). After surgery, patients received intravenous morphine sulfate or hydromorphone $\mathrm{HCl}$, as needed, to manage postsurgical pain. After the patient's first request and receipt of opioid rescue medication, other analgesics were permitted in accordance with the site's standing orders and pain management protocol. The analgesic medication prescribed after hospital discharge was oxycodone with acetaminophen $(5 / 325 \mathrm{mg})$ in all patients.

All patients were discharged within 24 hours of study drug administration based on the hospital's predetermined care management plan. A follow-up visit was scheduled for postsurgical day 10 .

\section{Assessments}

The primary efficacy measure was the duration of analgesia, as measured by time to first opioid administration after TAP infiltration. Key secondary measures included total postsurgical opioid use from TAP infiltration through hospital discharge, reported as morphine equivalents; total postsurgical opioid use from hospital discharge through day 10 , reported as number of tablets of oxycodone with acetaminophen $(5 / 325 \mathrm{mg})$; incidence of opioid-related AEs (somnolence, respiratory depression, hypoventilation, hypoxia, dry mouth, nausea, vomiting, constipation, sedation, confusion, pruritus, or ileus) until time of discharge; postsurgical pain intensity, as assessed by the patient on an 11-point numeric rating scale $(0=$ no pain, $10=$ worst possible pain) ${ }^{13}$ at $1,2,6,12,24,48,72$, and 96 hours after the surgery and at follow-up on day 10 (patients discharged from the hospital were to be contacted by telephone at the scheduled time points and asked to record their pain intensity scores); postsurgical pain intensity, as assessed by the health care provider on an 11-point numeric rating scale $(0=$ no pain, $10=$ worst possible pain), ${ }^{13}$ at $1,2,6,12$, and 24 hours after the surgery; and patient satisfaction with postsurgical pain control, rated on a 5-point Likert scale (1=extremely dissatisfied, $2=$ dissatisfied, $3=$ neither satisfied nor dissatisfied, $4=$ satisfied, and 5=extremely satisfied), at discharge, 72 hours, and day 10.
Safety, including the incidence of AEs, serious AEs, and treatment-emergent AEs through day 10 ( \pm 3 days), was also assessed.

\section{Data analyses}

The safety analysis set included all patients who underwent the planned surgery and received any amount of liposome bupivacaine. The efficacy analysis set included all patients who underwent the planned surgery and received bilateral TAP infiltration with liposome bupivacaine. All analyses were summarized with descriptive summary statistics.

\section{Results}

Twenty-four consecutive patients provided informed consent, were enrolled in the study, and were included in the primary safety and efficacy analysis sets. Of these, 21 patients completed the study (ten in the $20 \mathrm{~mL}$ group and eleven in the $40 \mathrm{~mL}$ group). The three patients who did not complete the study refused to participate in the follow-up visit. Patient demographics and baseline characteristics were similar between patients receiving liposome bupivacaine $20 \mathrm{~mL}$ and those receiving liposome bupivacaine $40 \mathrm{~mL}$ (Table 1).

Table I Patient demographics and baseline characteristics (safety analysis set)

\begin{tabular}{|c|c|c|c|}
\hline Variable & $\begin{array}{l}\text { Liposome } \\
\text { bupivacaine } \\
20 \mathrm{~mL} \\
(\mathrm{n}=\mid 2)\end{array}$ & $\begin{array}{l}\text { Liposome } \\
\text { bupivacaine } \\
40 \mathrm{~mL} \\
(\mathrm{n}=12)\end{array}$ & $\begin{array}{l}\text { Total } \\
(\mathrm{N}=24)\end{array}$ \\
\hline \multicolumn{4}{|l|}{ Age, years } \\
\hline Mean ( $\pm S D)$ & $60.7( \pm 7.2)$ & $61.7( \pm 7.0)$ & $61.2( \pm 7.0)$ \\
\hline Median & 63.5 & 61.5 & 62.0 \\
\hline Minimum, maximum & 45,68 & 50,73 & 45,73 \\
\hline \multicolumn{4}{|l|}{ Age category, n (\%), years } \\
\hline$<65$ & $6(50.0)$ & $9(75.0)$ & $15(62.5)$ \\
\hline$\geq 65$ & $6(50.0)$ & $3(25.0)$ & $9(37.5)$ \\
\hline \multicolumn{4}{|l|}{ Race, n (\%) } \\
\hline White & $12(100.0)$ & $12(100.0)$ & $24(100.0)$ \\
\hline \multicolumn{4}{|l|}{ Ethnicity, n (\%) } \\
\hline Hispanic or Latino & I (8.3) & 0 & I (4.2) \\
\hline Not Hispanic or Latino & II (9I.7) & $12(100.0)$ & $23(95.8)$ \\
\hline \multicolumn{4}{|c|}{ Height, cm } \\
\hline Mean $( \pm S D)$ & $176.6( \pm 6.6)$ & $178.8( \pm 8.8)$ & I $77.7( \pm 7.7)$ \\
\hline Median & 176.5 & 177.8 & 177.8 \\
\hline Minimum, maximum & 163,188 & 163,193 & 163,193 \\
\hline \multicolumn{4}{|l|}{ Weight, kg } \\
\hline Mean $( \pm S D)$ & $88.5( \pm \mid 4.4)$ & $89.4( \pm 20.5)$ & $89.0( \pm 17.4)$ \\
\hline Median & 88.0 & 88.5 & 88.5 \\
\hline Minimum, maximum & $65.8,111$ & $59.9,128$ & $59.9,128$ \\
\hline \multicolumn{4}{|l|}{ ASA class, $n(\%)$} \\
\hline I & 0 & 0 & 0 \\
\hline 2 & $8(66.7)$ & II (9I.7) & $19(79.2)$ \\
\hline 3 & $4(33.3)$ & I (8.3) & $5(20.8)$ \\
\hline
\end{tabular}

Abbreviations: ASA, American Society of Anesthesiologists; SD, standard deviation. 
Table 2 Cumulative number of oxycodone/acetaminophen (5/325 mg) tablets (mean [ \pm standard deviation]) consumed postdischarge (efficacy analysis set)

\begin{tabular}{lll}
\hline Time & Liposome bupivacaine, & Liposome bupivacaine, \\
point & $\mathbf{2 0 ~} \mathbf{~ L L}(\mathbf{n}=\mathbf{1 2})$ & $\mathbf{4 0 ~} \mathbf{~ L L}(\mathbf{n = 1 2 )}$ \\
\hline 48 hours & $1.9( \pm 2.1)$ & $2.2( \pm 2.1)$ \\
72 hours & $2.8( \pm 3.2)$ & $3.4( \pm 3.8)$ \\
96 hours & $3.7( \pm 4.3)$ & $4.8( \pm 5.3)$ \\
Day I0 & $6.3( \pm 8.9)$ & $6.1( \pm 7.4)$ \\
\hline
\end{tabular}

No patients in either treatment group regularly took any opioids within the 3 months before surgery.

\section{Efficacy}

Median time to first opioid administration after TAP infiltration, the primary efficacy measure, was similar in the $20 \mathrm{~mL}$ liposome bupivacaine group (23 minutes; 95\% confidence interval (CI), 14-42) and the $40 \mathrm{~mL}$ group (26 minutes; 95\% CI, 11-37). The mean ( \pm standard deviation) total amount of postsurgical opioids used during hospitalization (reported in morphine equivalents) was $25.4 \mathrm{mg}( \pm 9.2 \mathrm{mg})$ in the $20 \mathrm{~mL}$ liposome bupivacaine group and $27.3 \mathrm{mg}( \pm 8.5 \mathrm{mg})$ in the $40 \mathrm{~mL}$ group. From hospital discharge until the final visit on day 10 , both liposome bupivacaine groups required a mean of 0.7 oxycodone/acetaminophen $(5 / 325 \mathrm{mg})$ tablets per day (Table 2). No opioid-related AEs were reported in patients in either treatment group at the time of discharge.

Mean pain intensity scores over the first postoperative day and successive measurement times were similar for patients receiving either the lower-volume or higher-volume TAP infiltration with liposome bupivacaine (Figure 1). Mean pain scores were 4.4 and 5.3, respectively, at 1 hour postsurgery, and 3.1 and 3.9 , respectively, at 2 hours postsurgery in the liposome bupivacaine $20 \mathrm{~mL}$ and $40 \mathrm{~mL}$ groups; neither group had mean scores above 3.0 at any point after 2 hours. Similar findings were reported for the health care providerassessed pain intensity scores, with reported scores of 3.0 or lower at each point after 2 hours postsurgery.

Patient satisfaction with postsurgical pain control was comparable in both groups at discharge, 72 hours, and

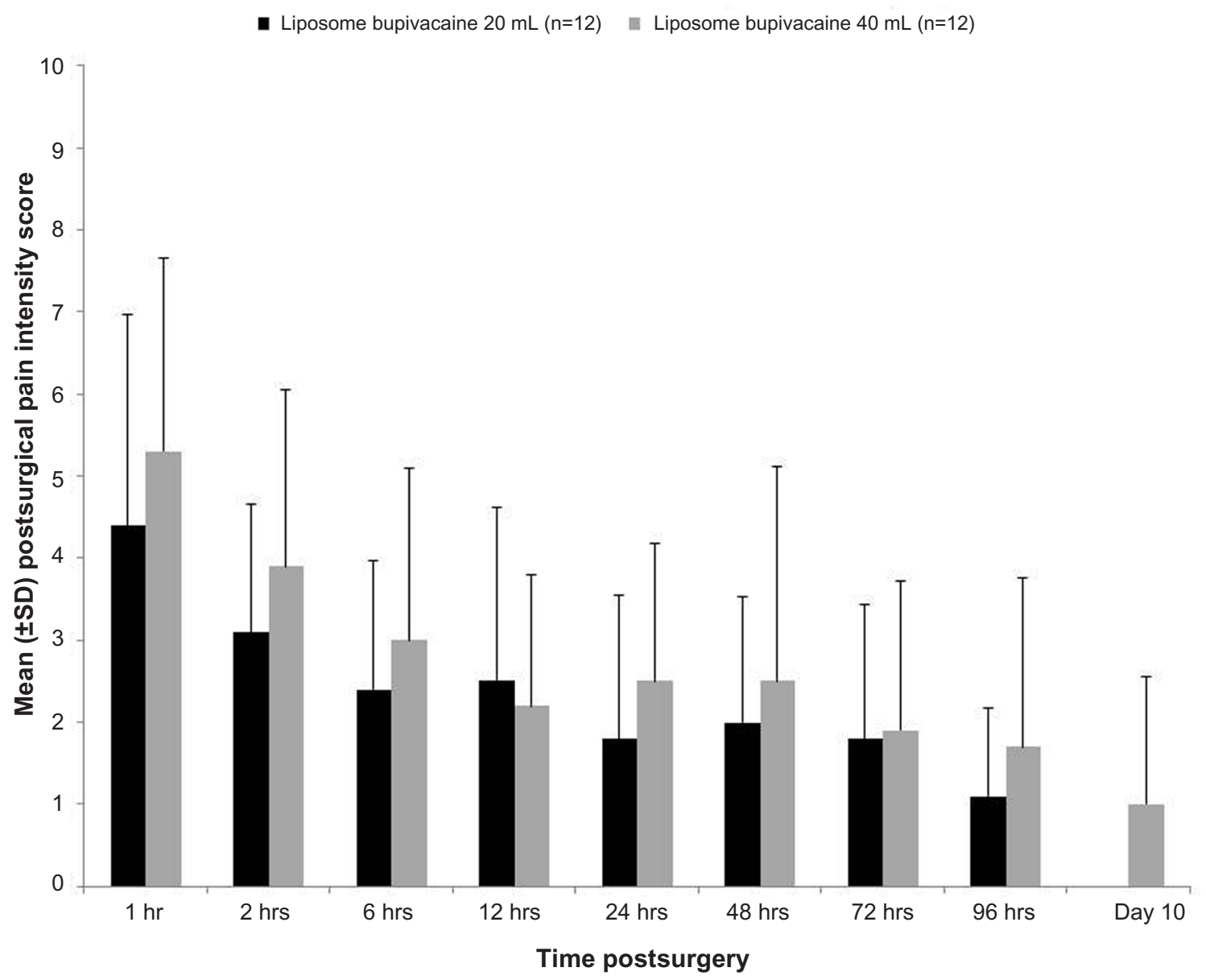

Figure I Mean ( \pm standard deviation [SD]) pain intensity scores, as assessed by the patient (efficacy analysis set). Note: Pain scores are based on a numeric rating scale, where $0=$ no pain and $10=$ worst possible pain. 
Table 3 Patient satisfaction ratings

\begin{tabular}{|c|c|c|c|c|c|c|}
\hline \multirow[t]{2}{*}{ Variable } & \multicolumn{2}{|l|}{ Discharge } & \multicolumn{2}{|l|}{72 hours } & \multicolumn{2}{|c|}{ Postsurgical day I0 } \\
\hline & $\begin{array}{l}\text { Liposome } \\
\text { bupivacaine, } \\
20 \mathrm{~mL}(\mathrm{n}=12)\end{array}$ & $\begin{array}{l}\text { Liposome } \\
\text { bupivacaine, } \\
40 \mathrm{~mL}(\mathrm{n}=12)\end{array}$ & $\begin{array}{l}\text { Liposome } \\
\text { bupivacaine, } \\
20 \mathrm{~mL}(\mathrm{n}=\text { I I) }\end{array}$ & $\begin{array}{l}\text { Liposome } \\
\text { bupivacaine, } \\
40 \mathrm{~mL}(\mathrm{n}=1 \mathrm{I})\end{array}$ & $\begin{array}{l}\text { Liposome } \\
\text { bupivacaine, } \\
20 \mathrm{~mL}(\mathrm{n}=\mathrm{I} \text { I) }\end{array}$ & $\begin{array}{l}\text { Liposome } \\
\text { bupivacaine, } \\
40 \mathrm{~mL}(\mathrm{n}=1 \text { I) }\end{array}$ \\
\hline Satisfied, n (\%) & $4(33)$ & $5(42)$ & $4(36)$ & $4(36)$ & $3(27)$ & $4(36)$ \\
\hline $\begin{array}{l}\text { Extremely } \\
\text { satisfied, n (\%) }\end{array}$ & $8(67)$ & 7 (58) & $7(63)$ & $7(64)$ & $8(73)$ & $7(64)$ \\
\hline
\end{tabular}

day 10 , with all patients in both groups reporting they were "satisfied" or "extremely satisfied" with their pain control (Table 3). Responses for one patient in each group were not available at 72 hours and day 10 .

\section{Safety}

A total of three patients (12.5\%) experienced AEs during the study: two in the $20 \mathrm{~mL}$ liposome bupivacaine group (one postprocedural hematoma; one pulmonary embolism) and one in the $40 \mathrm{~mL}$ group (joint stiffness). None of these AEs were considered treatment-related by the investigators.

\section{Discussion}

In this exploratory study, liposome bupivacaine $266 \mathrm{mg}$ administered via TAP infiltration in the setting of robotic prostatectomy was well tolerated when given in a total volume of 20 or $40 \mathrm{~mL}$, with no treatment-related AEs reported in either treatment group. Median time to first postsurgical opioid administration was similar in both groups ( 23 minutes versus 26 minutes in the 20 and $40 \mathrm{~mL}$ groups, respectively), as was mean total amount of opioids consumed postsurgery through hospital discharge ( 25 and $27 \mathrm{mg}$, respectively) and mean number of oxycodone/acetaminophen $(5 / 325 \mathrm{mg})$ tablets consumed per day after discharge until day 10 ( 0.7 tablets/day in both groups). All patients were satisfied with their postsurgical pain control.

The extent of dermatomal spread with TAP infiltration may be dependent on the volume of local anesthetic injected.${ }^{14}$ It is possible that increased volume may improve the extent of nerve coverage with TAP infiltration. In this study, liposome bupivacaine performed similarly in volumes of both 20 and $40 \mathrm{~mL}$; patient-assessed mean pain scores remained 3 or lower from 6 hours to up to 10 days after surgery in both treatment groups. However, the study was not powered to reach a definitive conclusion as to the effect of volume on the duration of analgesia with TAP blockade.

TAP infiltration has been associated with a number of favorable outcomes, including reductions in postoperative opioid requirements, improvements in pain scores, and reduced opioid-related adverse effects compared with traditional analgesic techniques. ${ }^{4-6}$ To our knowledge, this is the first published report of the use of liposome bupivacaine via TAP infiltration in the setting of robotic prostatectomy. Chow and colleagues ${ }^{10}$ recently presented results from a study comparing TAP infiltration with either bupivacaine $\mathrm{HCl}$ plus dexamethasone $(\mathrm{n}=25)$ or bupivacaine $\mathrm{HCl}$ alone $(n=22)$ in patients undergoing robotic prostatectomy. Patients in that study required totals of approximately 27.5-32.5 mg opioids through their hospital stay with similar or higher pain intensity scores than patients in the current study. ${ }^{15}$

This study has several inherent limitations. This was an open-label, nonrandomized, single-center, pilot study involving surgeries conducted by a single surgeon and TAP infiltration performed by three anesthesiologists in a small cohort of patients, with three patients (12.5\%) lost to follow-up. All patients were discharged from the hospital within 24 hours of study drug administration. Thus, it was not possible to control for patients' use of any non-protocolspecified analgesics. Further, the study was not powered formally to be able to determine the differences in efficacy between these two different volumes of liposome bupivacaine tested. No concurrent control group with bupivacaine $\mathrm{HCl}$ was studied. As such, results should be interpreted with caution and only suggest that use of liposome bupivacaine for TAP infiltration is feasible. On the basis of initial findings from this pilot study, larger, randomized, well-powered, and controlled studies may be warranted to assess the efficacy and safety of liposome bupivacaine via TAP infiltration in abdominal/pelvic surgical procedures.

\section{Conclusion}

In this pilot study, liposome bupivacaine performed similarly in volumes of both 20 and $40 \mathrm{~mL}$. Mean patient-assessed pain intensity scores remained 3 or lower from 6 hours to up to 10 days after surgery. No treatment-related adverse events were reported in the study. 


\section{Acknowledgments}

This study was funded by Pacira Pharmaceuticals, Inc. Editorial and writing assistance was provided by Bina J Patel, PharmD, from Peloton Advantage, LLC, supported by Pacira Pharmaceuticals, Inc. The authors were fully responsible for the content, editorial decisions, and opinions expressed in the current article. The authors did not receive an honorarium related to the development of this manuscript.

\section{Disclosure}

AS has been a speaker for Pacira Pharmaceuticals, Inc. with regard to liposome bupivacaine. UV has received study/ research grants from Pacira Pharmaceuticals, Inc. IAT is a consultant/advisor for Ethicon and Intuitive Surgical, Inc. and a stock/shareholder in Cambridge Endoscopic Devices, Inc. MS and GR report no conflicts of interest in this work.

\section{References}

1. American Society of Anesthesiologists Task Force on Acute Pain Management. Practice guidelines for acute pain management in the perioperative setting: an updated report by the American Society of Anesthesiologists Task Force on Acute Pain Management. Anesthesiology. 2012;116(2):248-273.

2. Taylor R Jr, Pergolizzi JV, Sinclair A, et al. Transversus abdominis block: clinical uses, side effects, and future perspectives. Pain Pract. 2013;13(4):332-344.

3. Jin F, Chung F. Multimodal analgesia for postoperative pain control. J Clin Anesth. 2001;13(7):524-539.

4. Findlay JM, Ashraf SQ, Congahan P. Transversus abdominis plane (TAP) blocks-a review. Surgeon. 2012;10(6):361-367.

5. Johns N, O’Neill S, Ventham NT, Barron F, Brady RR, Daniel T. Clinical effectiveness of transversus abdominis plane (TAP) block in abdominal surgery: a systematic review and meta-analysis. Colorectal Dis. 2012;14(10):e635-e642.
6. Charlton S, Cyna AM, Middleton P, Griffiths JD. Perioperative transversus abdominis plane (TAP) blocks for analgesia after abdominal surgery. Cochrane Database Syst Rev. 2010;(12):CD007705.

7. McDonnell JG, O’Donnell B, Curley G, Heffernan A, Power C, Laffey JG. The analgesic efficacy of transversus abdominis plane block after abdominal surgery: a prospective randomized controlled trial. Anesth Analg. 2007;104(1):193-197.

8. Carney J, McDonnell JG, Ochana A, Bhinder R, Laffey JG. The transversus abdominis plane block provides effective postoperative analgesia in patients undergoing total abdominal hysterectomy. Anesth Analg. 2008;107(6):2056-2060.

9. Sforza M, Andjelkov K, Zaccheddu R, Nagi H, Colic M. Transversus abdominis plane block anesthesia in abdominoplasties. Plast Reconstr Surg. 2011;128(2):529-535.

10. Chow C-H, Murthy AS, Daha AK, Tuerk IA, Sternlicht AL. Prospective, blinded, randomized evaluation of dexamethasone efficacy as adjunct to bupivacaine in transversus abdominis plane (TAP) block. Presented at: Annual Spring Meeting of the American Society of Regional Anesthesia and Pain Medicine; May 5-8; 2011; Las Vegas, NV.

11. Gorfine SR, Onel E, Patou G, Krivokapic ZV. Bupivacaine extendedrelease liposome injection for prolonged postsurgical analgesia in patients undergoing hemorrhoidectomy: a multicenter, randomized, double-blind, placebo-controlled trial. Dis Colon Rectum. 2011;54(12): 1552-1559.

12. International Conference on Harmonisation Working Group. ICH Harmonised Tripartite Guideline: Guideline for Good Clinical Practice E6 (R1). International Conference on Harmonisation of Technical Requirements for Registration of Pharmaceuticals for Human Use. June 10; 1996; Washington, DC. Available from: http://www.ich.org/ fileadmin/Public_Web_Site/ICH_Products/Guidelines/Efficacy/E6/ E6_R1_Guideline.pdf. Accessed September 8, 2014.

13. Dworkin RH, Turk DC, Farrar JT, et al; IMMPACT. Core outcome measures for chronic pain clinical trials: IMMPACT recommendations. Pain. 2005;113(1-2):9-19.

14. Abdallah FW, Chan VW, Brull R. Transversus abdominis plane block: a systematic review. Reg Anesth Pain Med. 2012;37(2):193-209.

15. Sternlicht A, Shapiro M, Robelen G, Vellayappan U, Pitts R, Tuerk IA. Initial findings using EXPAREL ${ }^{\circledR}$ (bupivacaine liposome injectable suspension) via infiltration into the transversus abdominis plane for postsurgical analgesia in robotic prostatectomy. Presented at: Annual Fall Pain Meeting and Workshops of the American Society of Regional Anesthesia and Pain Medicine; November 15-18; 2012; Miami Beach, FL.
Local and Regional Anesthesia

\section{Publish your work in this journal}

Local and Regional Anesthesia is an international, peer-reviewed, open access journal publishing on the development, pharmacology, delivery and targeting and clinical use of local and regional anesthetics and analgesics. The journal welcomes submitted papers covering original research, basic science, clinical studies, reviews \& evaluations,

\section{Dovepress}

guidelines, expert opinion and commentary, case reports and extended reports. The manuscript management system is completely online and includes a very quick and fair peer-review system, which is all easy to use. Visit http://www.dovepress.com/testimonials.php to read real quotes from published authors. 